\title{
Perception and acceptability of bilateral tubal ligation among women attending antenatal clinic at Usmanu Danfodiyo university teaching hospital Sokoto
}

\section{Ahmed Yakubu ${ }^{1 *}$, Tukur Dabo Sagir ${ }^{2}$, Abubakar Panti ${ }^{1}$, Garba Jamila A. ${ }^{2}$, Isah Usman Mani ${ }^{2}$, Anas Rabiu Funtua ${ }^{2}$, Aliyu Muhammed Chappa ${ }^{2}$, Mbakwe Markus ${ }^{2}$}

\author{
${ }^{1}$ Department of Obstetrics and Gynecology, Usmanu Danfodiyo University, Sokoto, Nigeria \\ ${ }^{2}$ Department of Obstetrics and Gynecology, Usmanu Danfodiyo University Teaching Hospital, Sokoto, Nigeria
}

Received: 30 January 2020

Revised: 21 February 2020

Accepted: 29 February 2020

\section{*Correspondence:}

Dr. Ahmed Yakubu,

E-mail: ahmeddryakubu@yahoo.com

Copyright: (C) the author(s), publisher and licensee Medip Academy. This is an open-access article distributed under the terms of the Creative Commons Attribution Non-Commercial License, which permits unrestricted non-commercial use, distribution, and reproduction in any medium, provided the original work is properly cited.

\begin{abstract}
Background: Contraception can be defined as all temporary or permanent measures designed to prevent pregnancy. Bilateral tubal ligation is a surgical and permanent form of contraception offered to women who completed their family size or for limitation of family size due to medical condition. The practices of bilateral tubal ligation is limited in Sub-Saharan African countries, Nigeria inclusive because of great desire for a large family size, cultural and religious factors, misunderstanding and fear of the procedure. The aim of the study was to determine the perception and acceptability of bilateral tubal ligation as a form of contraception among women attending Antenatal clinic at Usmanu Danfodiyo University Teaching Hospital Sokoto.

Methods: This was a cross sectional study conducted among women attending antenatal clinic between $1^{\text {st }}$ of May to $31^{\text {st }}$ of July, 2018. The information was obtained using a structured questionnaire to obtain the respondent's sociodemographic characteristics, questions on perception and acceptability of bilateral tubal ligation. Data analysis was done with statistical package for social sciences version 22 (SPSS Inc, Chicago, IL, USA).

Results: The study revealed that $73 \%$ of the respondents were aware of bilateral tubal ligation, but only $44 \%$ of them have good perception towards it. Majority of the respondents (63.8\%) reject BTL for contraception. Most of their reasons were cultural believe (33.3\%), regret (31.6\%), religious believe $(26.6 \%)$ and fear of surgery $(8.5 \%)$.

Conclusions: There was poor perception and low acceptability toward bilateral tubal ligation among the study population, mostly due to cultural and religious believes, as well as fear of regret, despite awareness of BTL among majority of the respondents.
\end{abstract}

Keywords: Complete family, Nigeria, Tubal ligation

\section{INTRODUCTION}

The provision and expansion of family planning services is a public health need and a national development priority for many countries across Sub-Saharan Africa. ${ }^{1}$ Contraception can be defined as all temporary or permanent measures, designed to prevent pregnancy. ${ }^{2}$
Bilateral tubal ligation (BTL), also called tubal occlusion or female sterilization is surgical procedure which aims at

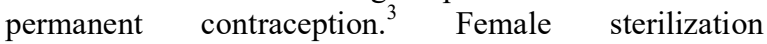
procedures were first performed in the late $1800 \mathrm{~s}$ but did not become widely available until 1930s when the Pomeroy technique for ligating the fallopian tubes was introduced. For several decades most of the procedures 
were performed for medical reasons. ${ }^{4}$ However, the increasing trend towards smaller families in developed countries coupled with the availability of new simpler, safer and more effective surgical techniques led to an increased demand for female sterilization. ${ }^{5-7}$

The United Nation estimates that 180 million couples have relied on surgical contraception to limit their families worldwide. ${ }^{8,9}$ An estimate of about 700,000 female sterilization procedures were performed each year. ${ }^{10}$ However, female sterilization is practice to a limited extent in African countries because of the aversion to the procedure. ${ }^{7,11,12}$ In Nigeria the acceptance rate of female sterilization is also low. ${ }^{4,13}$ The reasons for this low acceptance were rumours, misunderstanding and fear of a variety of health risk though to be associated with the procedure. Other limiting factors includes religious and cultural factors, great desire for a large family size, inadequate facilities, shortage of trained personnel and high infants and childhood mortality. ${ }^{4,13,14}$

The surgical approaches for BTL include laparoscopy, laparotomy (concurrent with caesarean section) and minilaparotomy. The laparoscopic approach is the preferred route for interval BTL procedures, whereas minilaparotomy is used for post-partum BTL. ${ }^{5,8,15}$

Bilateral tubal ligation has an important role on prevention of unplanned pregnancy and reduction of maternal mortality. The aim of this study was to determine the perception and acceptability of bilateral tubal ligation as a form of contraception among pregnant women attending antenatal clinic at Usmanu Danfodiyo University Teaching Hospital.

\section{METHODS}

This study was a cross sectional study among pregnant women attending ante-natal clinic at Usmanu Danfodiyo University Teaching Hospital Sokoto, within the period of three months (between $1^{\text {st }}$ May, 2018 to $31^{\text {st }}$ July, 2018).

The minimum sample size for the study was obtained using an acceptance rate of bilateral tubal ligation for contraception of $21.7 \%$ from a previous study done in Jos. ${ }^{16}$ The minimum sample size obtained was 282. Simple random sampling technique (by balloting) was used to select the participants and a verbal consent was obtained. Self-administered/interviewer questionnaires were administered to the participants. The questionnaires were used to obtain information on socio-demographic characteristics, knowledge, perception and acceptability of bilateral tubal ligation.

\section{Statistical analysis}

Data analysis was done with statistical package for social Sciences version 22 (SPSS Inc, Chicago, IL, USA).

\section{RESULT}

Most of the respondents were between the ages of 25 to 29 years. The youngest was 20 years while the eldest was 45 years. Majority of the participants were Hausa/Fulani (56.7\%), followed by Yorubas (15.6\%). Most of them were Muslim (77.7\%) and all were married. Most of them were also in monogamous setting $(74 \%)$. The sociodemographic characteristic of the respondents is shown in Table 1.

Table 1: Socio-demographic characteristics of the respondents.

\begin{tabular}{|c|c|c|}
\hline Characteristics & Frequency & Percentage \\
\hline \multicolumn{3}{|l|}{ Age } \\
\hline Less than 20 years & 0 & $0 \%$ \\
\hline 20 to 24 years & 79 & $28.0 \%$ \\
\hline 25 to 29 years & 97 & $34.4 \%$ \\
\hline 30 to 34 years & 69 & $24.5 \%$ \\
\hline Above 35 years & 37 & $13.1 \%$ \\
\hline \multicolumn{3}{|l|}{ Ethnicity } \\
\hline Hausa/Fulani & 160 & $56.7 \%$ \\
\hline Igbo & 36 & $12.8 \%$ \\
\hline Yoruba & 44 & $15.6 \%$ \\
\hline Others & 42 & $14.9 \%$ \\
\hline \multicolumn{3}{|l|}{ Religion } \\
\hline Islam & 219 & $77.7 \%$ \\
\hline Christianity & 63 & $22.3 \%$ \\
\hline \multicolumn{3}{|l|}{ Family setting } \\
\hline Monogamous & 211 & $74.8 \%$ \\
\hline Polygamous & 71 & $25.2 \%$ \\
\hline \multicolumn{3}{|l|}{ Occupation } \\
\hline House wife & 84 & $29.8 \%$ \\
\hline Petty trader & 35 & $12.4 \%$ \\
\hline Business & 33 & $11.7 \%$ \\
\hline Civil servant & 100 & $35.5 \%$ \\
\hline Student & 30 & $10.6 \%$ \\
\hline \multicolumn{3}{|l|}{ Educational status } \\
\hline No formal education & 3 & $01.1 \%$ \\
\hline Primary & 4 & $01.4 \%$ \\
\hline Secondary & 86 & $30.5 \%$ \\
\hline Tertiary & 189 & $67.0 \%$ \\
\hline \multicolumn{3}{|l|}{ Parity } \\
\hline Primigravida & 10 & $03.5 \%$ \\
\hline Multigravida & 211 & $74.8 \%$ \\
\hline Grand multipara & 61 & $21.6 \%$ \\
\hline \multicolumn{3}{|c|}{ Number of living children } \\
\hline None & 14 & $05.0 \%$ \\
\hline One & 47 & $16.7 \%$ \\
\hline Two & 67 & $23.8 \%$ \\
\hline Three & 93 & $33.0 \%$ \\
\hline Four & 42 & $14.8 \%$ \\
\hline Five and above & 19 & $06.7 \%$ \\
\hline Total & 282 & $100 \%$ \\
\hline
\end{tabular}




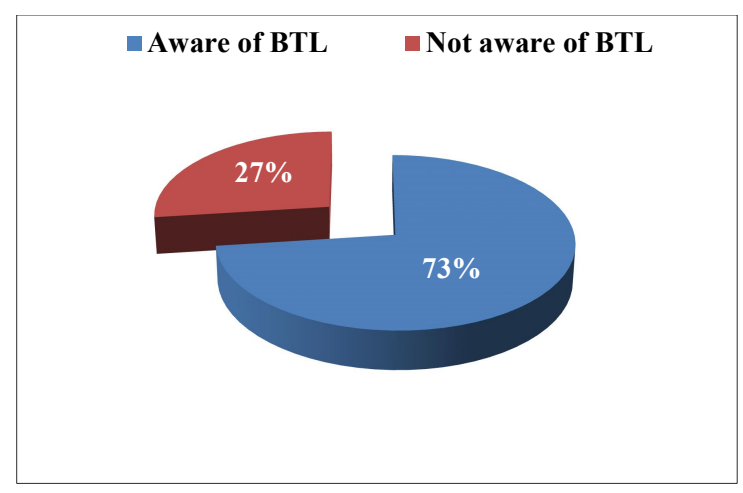

Figure 1: Awareness of BTL among the respondents.

Table 2: Knowledge and source of knowledge on BTL among the respondents.

\begin{tabular}{|l|ll|}
\hline Response & Frequency & Percentage \\
\hline What form of contraception is BTL? & \\
\hline Permanent & 169 & $59.9 \%$ \\
\hline Temporary & 28 & $09.9 \%$ \\
\hline I don't know & 85 & $30.1 \%$ \\
\hline \multicolumn{2}{|l|}{ Source of information } & \\
\hline Health workers & 102 & $36.2 \%$ \\
\hline Friends & 98 & $34.8 \%$ \\
\hline Radio/TV & 5 & $01.8 \%$ \\
\hline Internet & 1 & $0.4 \%$ \\
\hline None & 76 & $26.9 \%$ \\
\hline Total & 282 & $100 \%$ \\
\hline
\end{tabular}

Majority of the respondent (73\%) of the respondents were aware of bilateral tubal ligation and $36.2 \%$ of them heard it from the health workers (Figure 1), However, only 169 $(59.9 \%)$ knew that it is a form of permanent contraception (Table 2).

Among the respondents, $44 \%$ had good perception about BTL and $56 \%$ had poor perception (Figure 2). In addition, only $36.2 \%$ were willing to accept BTL for contraception (Figure 3). The main reasons where due to cultural desire for large family size and fear of regret. The various reasons for not accepting it are shown in Figure 4.

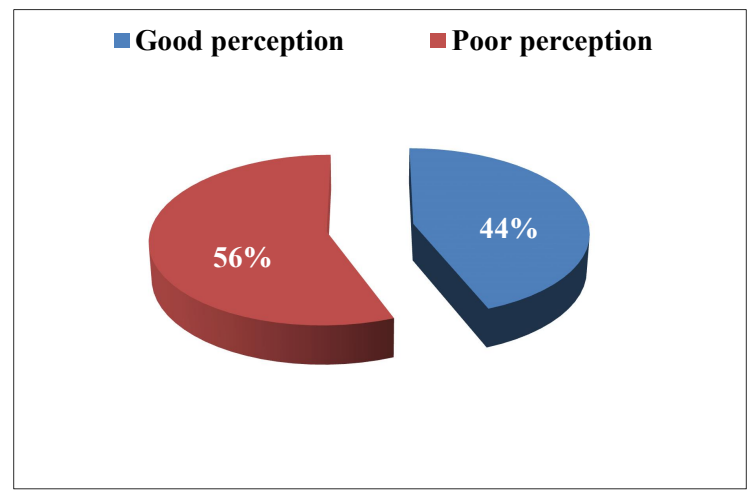

Figure 2: Perception on BTL among the respondents.

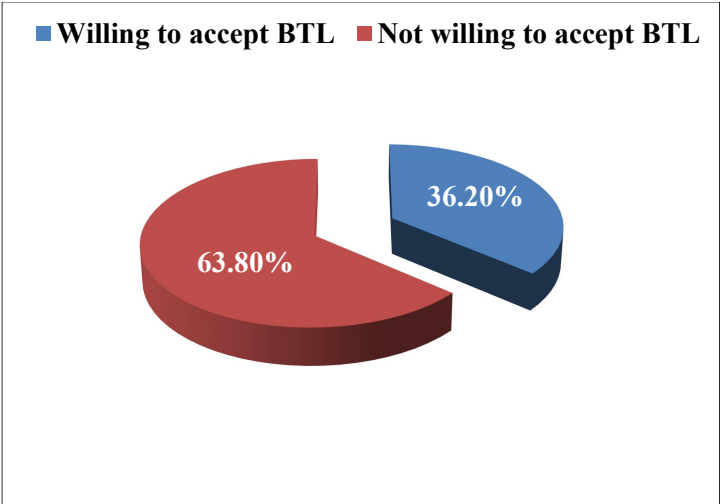

Figure 3: Acceptability of BTL among the respondents.

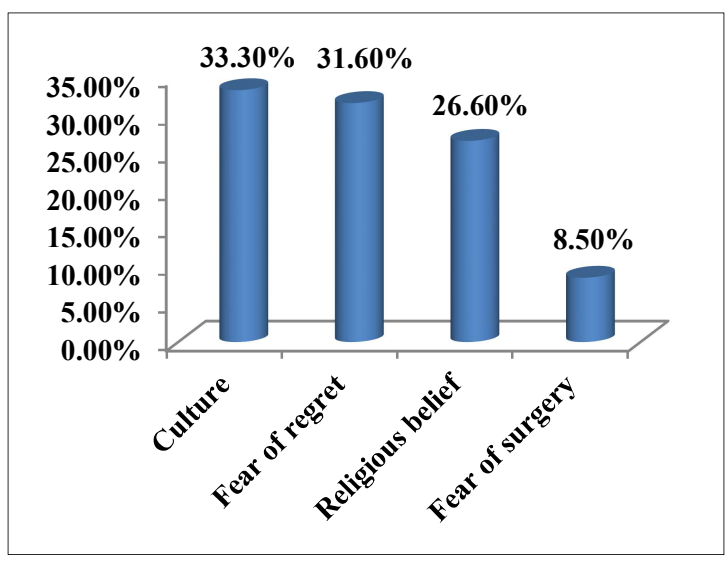

Figure 4: Reasons for not accepting BTL.

\section{DISCUSSION}

Age is an important factor when it comes to decision for permanent contraception. Majority of the participants belong to this age group of 26-30 years which is within the middle of the reproductive age. This is similar to a study carried out at Osogbo south west Nigeria. ${ }^{17}$

Majority of the participants in this study were aware of BTL, this is similar to another study done at Ado Ekiti southwest Nigeria in which all the participants were aware of BTL. ${ }^{18}$ However, despite the high level of awareness of BTL among the participant, majority of them believed it is bad and this is similar to the study at Ado Ekiti where $61.1 \%$ of the participants believed it is bad. ${ }^{18}$ This may be due to ignorance on what exactly BTL entails and the strong desire for large family size in African culture.

In general, the acceptance rate of BTL in Africa is low because of deep rooted socio-cultural and religious barriers, poverty, inadequate counseling as well as limited facilities. The acceptance rate of BTL in this study of $36.2 \%$ is higher compared to a study done at Jos north central Nigeria in which the acceptance rate was 
$21.7 \%{ }^{16}$ This may be because majority of the participants in this study were aware of BTL, had tertiary level of education and most of them were civil servants.

Most of the reasons given by the participants in this study, why they cannot accept BTL for contraception includes: cultural believe which may be because majority of the participants in this study were Hausa/Fulani with cultural desire for large family size. Another reason is fear of regret for not being able to get another child again in case they lost the ones they had. This may be related to the high level of infants and childhood mortality rate in Sub-Saharan Africa. Religious believe is another reason given by some of the participants for not accepting BTL for contraception. These reasons are similar to the reasons given by the participants in a similar study conducted in Ado Ekiti. ${ }^{18}$

\section{CONCLUSION}

In conclusion, there is still high level of poor perception and low acceptability of bilateral tubal ligation as a form of contraception among the study population. The reasons for these were cultural and religious believes as well as fear of regret Therefore, more public enlightenment involving both the cultural and religious leaders as well as providing more measures to prevent infant and childhood mortality will go a long way in improving the acceptance rate of bilateral tubal ligation.

Funding: No funding sources

Conflict of interest: None declared

Ethical approval: The study was approved by the Institutional Ethics Committee

\section{REFERENCES}

1. Gordon Maclean C, Rodriguez MI. The safety, efficacy and acceptability of task sharing tubal sterilization to midlevel providers: a systematic review. Contracept. 2014;89(6):504-11.

2. Hiralal K. Contraception In: Dutta DC ed. Textbook of Gynecology Revised $6^{\text {th }}$ Ed. Jaypee Brothers Medical Publishers(p) Ltd (New Delhi, London); 2013:P475.

3. Adeleye JA. Female sterilization by laparotomy and tubal ligation (Ibadan experience). Trop J Obstet Gynaecol. 1991;2(1):91-4.

4. Salaudeen G, Jimoh A, Panti A, Sa'idu R, Balogun R. Female surgical sterilization at university of Ilorin Teaching Hospital, Ilorin: a 10 year review. Orient J Med. 2012;24:1-2

5. Schmidt E, Diedrich J, Eisenberg L. Surgical procedures for Tubal Sterilization Glob. Libr.
Women's Med. (ISSN: 1756-2228) 2014; DOI 10.3843/GLOWM.10400. 2014.

6. World Health Organization. Female sterilization: a guide to provision of services. Geneva: World Health Organization; 1992. Available at: https://apps.who.int/iris/handle/10665/40133. Accessed on $25^{\text {th }}$ January 2020.

7. Liskin L, Rinehart W, Blackburn R, Rutledge AH. Minilaparotomy and laparoscopy: safe, effective, and widely used. Population reports (Washington, DC). Series C, Female Sterilization. 1985;9:C125-67.

8. Kansu Celik H, Uygur D, Tasci Y, Durmus M, Kisa karakaya B, Engin Ustun Y. Female sterilization by tubal ligation during caesarean section in women with 2 or more previous caesarean sections. Gynaecol Obstet Reprod Med. 2018;24(1):7-11.

9. United Nations. Dept. of International Economic. Levels and trends of contraceptive use as assessed in 1988. United Nations Publications; 1989. Available at: htpps://digitallibrary.un.org/recoers/63527. Accessed on $11^{\text {th }}$ February 2020.

10. Sterilization B. ACOG technical bulletin. Int J Gynecol Obstet. 1996;53:281-8.

11. Ogunniyi SO, Faleyimu BL, Ifaturoti O. Female surgical contraception in Ile-Efe: An eight-year Review. Niger Med Pract. 1991;21(6):72-4.

12. Family planning Worldwide, 2002 Data Sheet. Available at: htpps://www.prb.org/familyplaning worldwide2002datasheet. Accessed on $11^{\text {th }}$ February 2020.

13. Attah Raphael A, Omole Ohous A. Bilateral tubal ligation at Aminu Kano Teaching Hospital: a five years review. Bo Med J. 2014;11(1):57-64.

14. Onifade O, Ogungboye R, Adigun J, Abikoye A, Abiola O, Aliyu S. Socio-cultural factors influencing choice of bilateral tubal ligation among women attending University of Ilorin Teaching Hospital. KIU J Social Sci. 2017;3(1):37-46.

15. Skar AJ. Tubal sterilization. eMed J. 2001;2(9):1-17.

16. Mutihir JT, Pam VC. Overview of contraceptives use in Jos University Teaching Hospital, North central Nigeria. J Clin Pract. 2008;11:139-43.

17. Adebimpe WO. A survey of clients and ethical perspectives of voluntary tubal ligations in the southwestern Nigeria. J Basic Clin Reprod Sci. 2016;5(1):21-6.

18. Akpor OA, Fadare RI, Ekanem EI. Knowledge and perception of women regarding bilateral tubal ligation in Southwest Nigeria. J Nurs Health Sci. 2016;5(5):31-6.

Cite this article as: Yakubu A, Sagir TD, Panti A, Jamila GA, Mani IU, Funtua AR, et al. Perception and acceptability of bilateral tubal ligation among women attending antenatal clinic at Usmanu Danfodiyo university teaching hospital Sokoto. Int J Reprod Contracept Obstet Gynecol 2020;9:1636-9. 